\title{
Dehydration of Organic Solutions by a Recirculated Air Sweep Pervaporation Process Using Anion-Exchange Hollow Fibers
}

\author{
Emanuel Korngold, Elisheva Zisner and Tony (Tuvia) Bejerano \\ Zuckerberg Institute for Water Research, Ben-Gurion University of the Negev, P.O. Box 653, Beer-Sheva \\ 84105, Israel
}

\begin{abstract}
An air sweep pervaporation process with thin anion-exchange hollow fibers was investigated for various water-organic solvent mixtures at different operating conditions. It was found that flux and separation factor increased with a decrease of the dielectric constant of the organic solvent. When the temperature of the process was increased, the flux increased. At feed temperatures of $65-70^{\circ} \mathrm{C}$ it was possible to reduce the water concentration in a $3-10 \%$ isopropyl alcohol (IPA) solution to $0.5 \%$. The energy requirement for decreasing the water concentration in IPA from 3$10 \%$ to $0.5 \%$ was $100-225 \mathrm{kWh}^{-1}$ ton $^{-1}$.
\end{abstract}

Keywords: Solvent dehydration, pervaporation, anion exchange hollow fibers, dielectric constant.

\section{INTRODUCTION}

Distillation is a commonly used method for the dehydration of organic solutions, but it is not always the method of choice. An efficient alternative is pervaporation with polyethylene ion-exchange membranes that are highly selective for water [1-4], especially for solutions with near-azeotropic compositions, for which conventional separation by distillation becomes particularly difficult. Previous theoretical and experimental research on the removal of water from mixtures of water and an alcohol has focused on the pervaporation of water-alcohol mixtures of various feed compositions and at different temperatures through cation-exchange polyethylene hollow fiber membranes of different capacities [3-6]. In contrast to these set-ups, our system for the removal of water from organic liquids by means of a pervaporation process is based on thin anion-exchange polyethylene hollow fiber membranes [7, 8], which have better chemical stability. The system is similar to that previously used for water desalination by pervaporation with anion-exchange hollow fiber membranes $[9,10]$.

In our recirculated air sweep pervaporation process (Figure 1), the water-organic liquid mixture is circulated through the inside of the anion-exchange hollow fibers. Water is selectively removed from the mixture by vaporization through the non-porous selective membrane. The water then evaporates from the outer side of the membrane and is removed by a stream of hot dry air circulated by a blower. Finally, the water vapor is condensed and removed, and the cooled air is heated again and recirculated. The flux of the water

*Address correspondence to this author at the Zuckerberg Institute for Water Research, Ben-Gurion University of the Negev, P.O. Box 653, Beer-Sheva 84105, Israel; Tel: +972 86461940; E-mail: korngold@bgu.ac.il

E-ISSN: 1929-6037/16 through the hollow fibers is a function of the concentration of the water in the organic liquid, the type of the organic component, the membrane thickness, and the operating temperature, as will be shown below.

In addition to its suitability for the removal of water from azeotropic mixtures, ion-exchange pervaporation process offers a number of other advantages: 1) Highly efficient water removal is obtained because water, which has a high dielectric constant (80), diffuses faster through the continuous path of the ion hydration shells than organic liquids, which have lower dielectric constants. 2) The process is suitable for the removal of water generated in the course of certain chemical reactions. Removal of water in situ from the system causes a shift in the equilibrium, and the efficiency of the reaction can thus be improved. Moreover in case of hollow fibers, the flux can be increased by a reduction in the wall thickness of the anion-exchange membrane, without causing significant damage to the mechanical properties of the hollow fiber membrane, rather than in case of a thin sheet.

The goal of the current research was to investigate the efficiency of pervaporation using thin anionexchange hollow fibers (having wall thickness of 80 $100 \mu \mathrm{m})$ in the separation of mixtures of water and various miscible organic liquids. The effects of the following operation parameters on the efficiency of the process were investigated in a bench-scale unit and in a pilot plant: the dielectric constant of the organic solvent, the process temperature $\left(50-70^{\circ} \mathrm{C}\right)$, the cooling temperature, and the flow rate of the circulated air.

\section{EXPERIMENTAL}

\subsection{Membrane Manufacturing}

The anion-exchange hollow fibers were prepared inhouse by sulfochlorination, amination and quaterni๑) 2016 Lifescience Global 


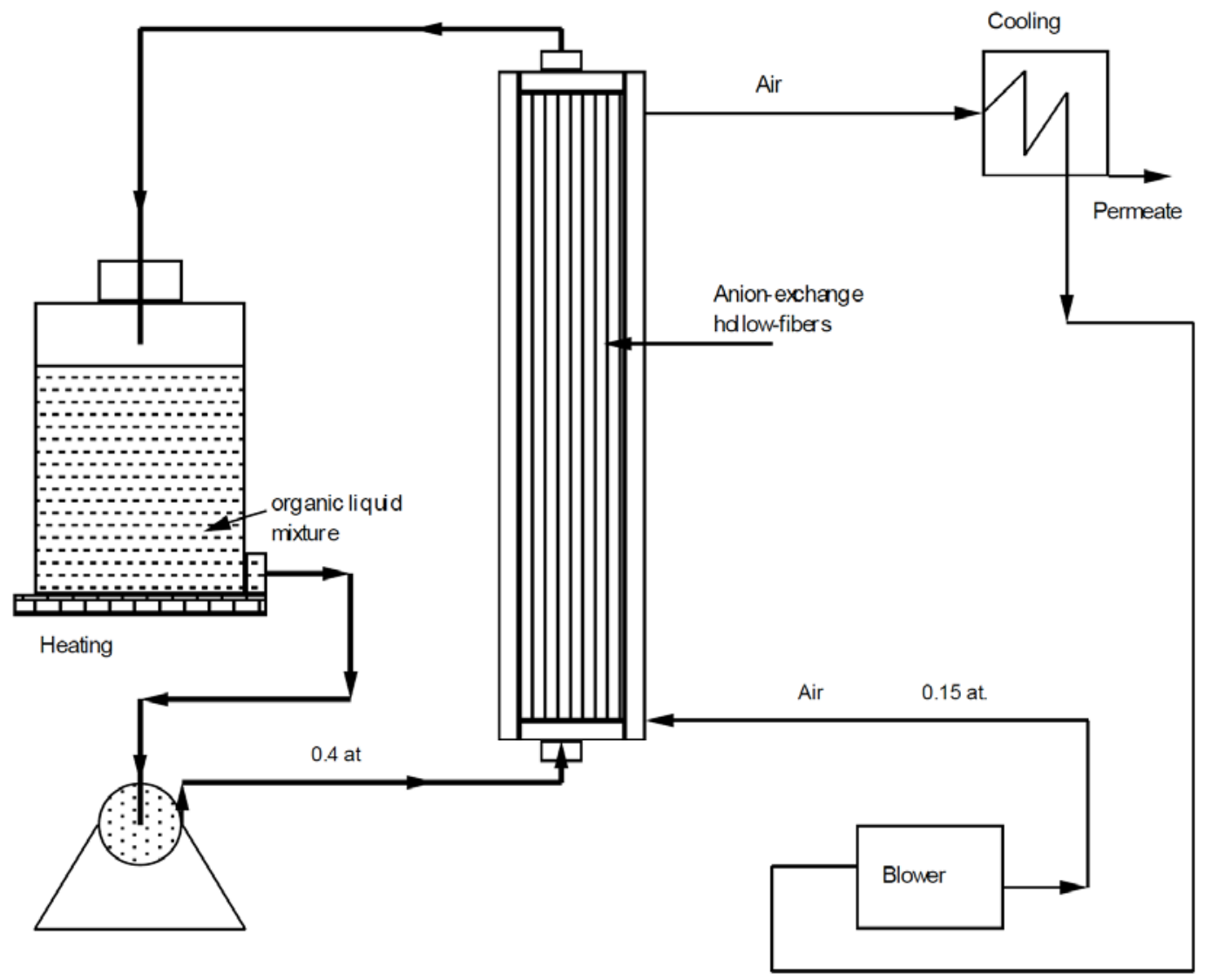

Figure 1: Flow sheet of our recycled air sweep pervaporation system.

zation of polyethylene hollow fibers. The starting product was commercial low-density polyethylene, which was extruded to produce hollow fibers of wall thickness 33-100 $\mu \mathrm{m}$, external diameter 0.3-1.0 mm and length $130 \mathrm{~cm}$. The hollow fibers were introduced into a glass tube, and a trichloroethylene solution containing $10-30 \%$ mixture of $\mathrm{Cl}_{2}+\mathrm{SO}_{2}$ was circulated through it at $15-20{ }^{\circ} \mathrm{C}$ for $6-12 \mathrm{~h}$ until the sulfur content reached $5-5.5 \%$ by weight. Sulfur content was determined by combustion of a hollow fiber sample in pure oxygen followed by titration of the formed sulphate with $\mathrm{Ba}\left(\mathrm{NO}_{3}\right)_{2}$. Two $100-\mathrm{W}$ light bulbs were used to provide illumination for the photochemical reaction. The hollow fibers were then washed by immersion in chloroform for a few hours, after which they were allowed to stand in dimethylaminopropylamine overnight. After washing with water and drying, the hollow fibers were quaternized by immersing them in dimethylformamide saturated with methyl bromide at $15-20^{\circ} \mathrm{C}$ for one day. Finally, the fibers were washed with methanol to remove any traces of the chemical reagents. The anion-exchange hollow fibers had a capacity of $0.8-0.9$ meq. ${ }^{-1}$ and swelling in water of 20 $25 \%$ these figures were measured by routine standard methods [11].

\subsection{Bench-Scale Unit}

Experiments were carried out in a bench-scale module of diameter of $12 \mathrm{~mm}$ that contained 60 hollow fibers of length $130 \mathrm{~cm}$, thickness $80-100 \mu \mathrm{m}$, and outside diameter about $0.8 \mathrm{~mm}$. The total surface area was about $0.2 \mathrm{~m}^{2}$. As shown in Figure 1, the feed solution at a temperature of $45-70^{\circ} \mathrm{C}$ was circulated inside the hollow fibers, and air was circulated outside the fibers to remove the permeate, which consisted mainly of water. To ensure high separation factor and to enable condensation and collection of the permeate, the air was cooled to 0 to $-5^{\circ} \mathrm{C}$ (in all the experiments). Thereafter, the air was heated and recirculated to the module (outside the hollow fibers).

\subsection{Pilot Plant Unit}

The pilot plant unit comprised 5-10 modules, each having a surface area of $1.2 \mathrm{~m}^{2}$. The dimensions of the hollow fibers were the same as those in the benchscale unit. The solution and the air were circulated through the unit in the same way as in the bench-scale unit, as shown in Figure 1. The two streams (solution and air) were continuously filtered through a 1- $\mu \mathrm{m}$ polypropylene cloth filter. The flow rate of the air was 


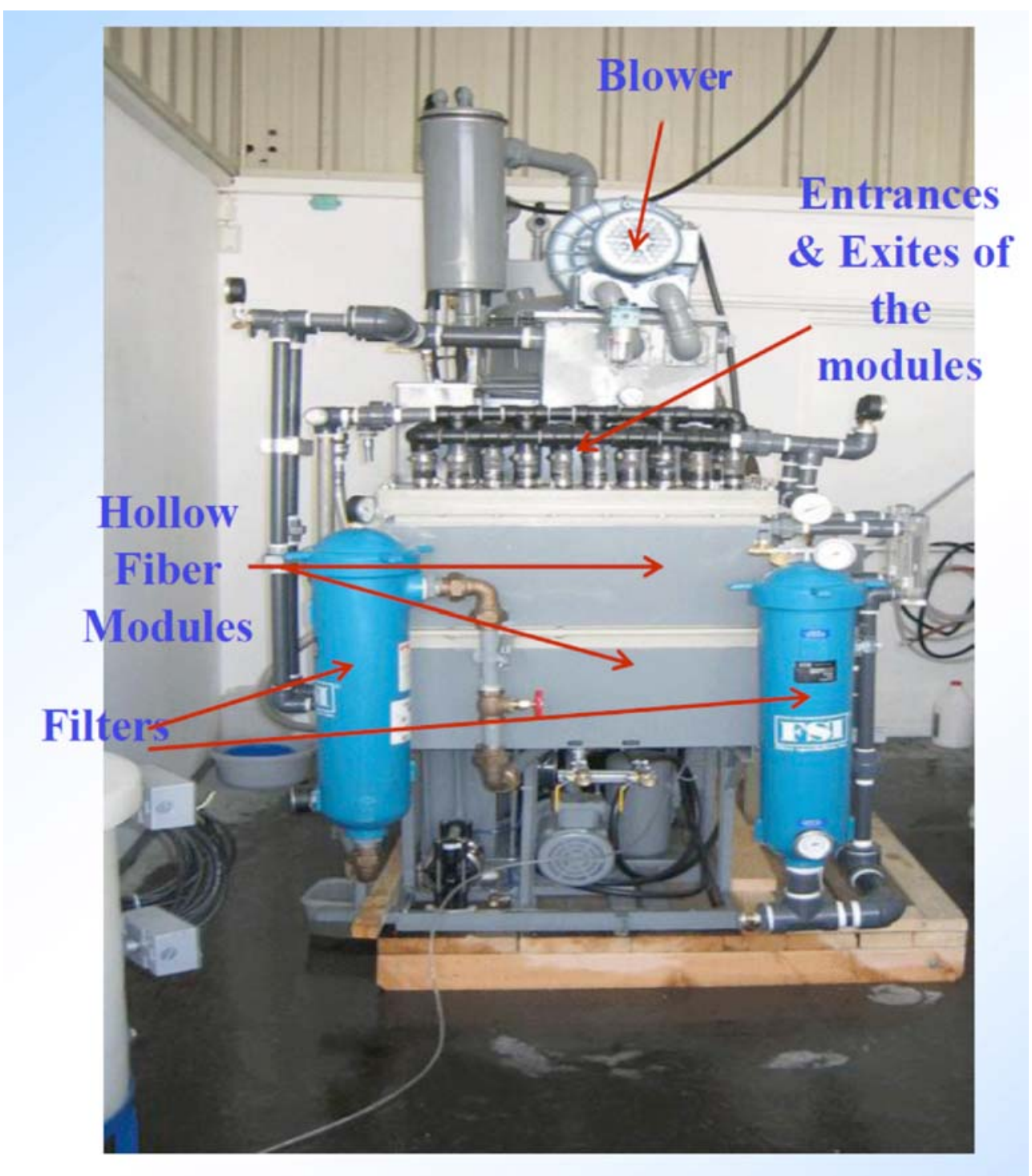

Figure 2: Pilot plant unit.

$50-70 \mathrm{~m}^{3} \mathrm{~h}^{-1}$, and that of solution was $250-600 \mathrm{~h}^{-1}$. After passing through the module, the air was cooled in the cooling unit to remove the permeate, which was mainly water. The air was then passed through a blower (compressor), where it was heated to $45^{\circ} \mathrm{C}$, and thereafter through the hot modules, where it was further heated to $50-55^{\circ} \mathrm{C}$. A picture of the pilot plant unit is given in Figure 2.

\section{RESULTS AND DISCUSSION}

To characterize the different parameters that influence the water flux and separation factor of the pervaporation process, experiments were carried out with various solvents at different experimental conditions in both the bench-scale unit and the pilot plant. It was found experimentally that to obtain optimal separation factorthe partial water vapor pressure on the downstream side of the membrane had to be lower than $5 \mathrm{~mm} \mathrm{Hg}$.

\subsection{Bench-Scale Unit}

\subsubsection{Influence of the Dielectric Constant on the Water Flux and Separation Factor}

Experiments on the pervaporation of various waterorganic liquids mixtures showed that the dielectric constant of the organic compound is an important parameter that influences both the water flux (Figure 3) and the separation factor (Figures 4 and 5), where the separation factor $\mathrm{S}(\mathrm{w} / \mathrm{s})$ is defined as:

$$
S_{(W / s)}=\left(X_{w} / X_{s}\right)^{P} /\left(X_{w} / X_{s}\right)^{F}
$$

where $X_{w}$ and $X_{s}$ denote weight fractions of water and solvent in the permeate $\left({ }^{P}\right)$ and the feed $\left({ }^{F}\right)$. 


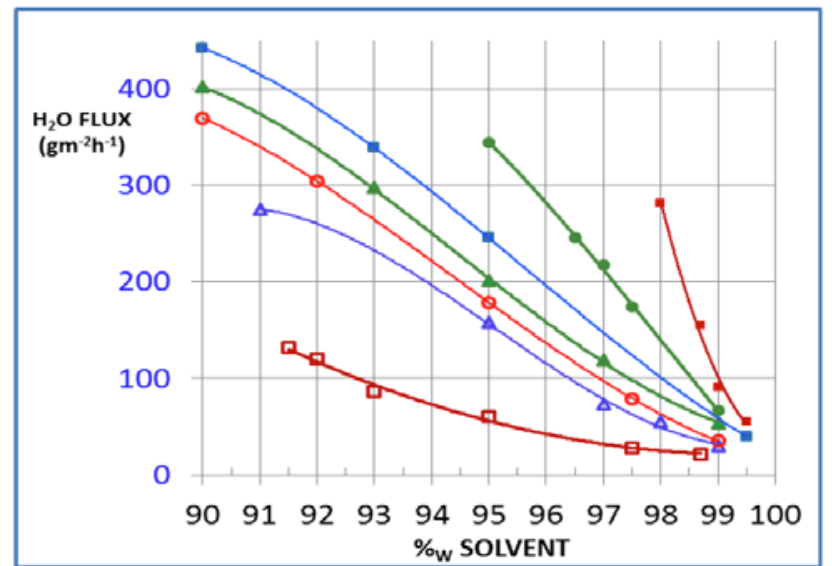

Figure 3: Influence of the dielectric constant $\varepsilon$ of various organic solvents on the water flux at different concentrations of the solvents at $70^{\circ} \mathrm{C}$. NMP (N-methyl-2-pyrrolidone), $\varepsilon=$ 32, -ם- ; ethanol, $\varepsilon=24.3,-\Delta$ - ; IPA (isopropyl alcohol), $\varepsilon=$ 18.3, -o- ; MEK (methyl ethyl ketone), $\varepsilon=18.3$, - $\Delta$ - ; ethyl lactate, $\varepsilon=13.1$, - - ; THF (tetrahydrofuran), $\varepsilon=7.4$, - - ; ethyl acetate, $\varepsilon=6.0$, - $\square-$.

The influence of the dielectric constant on the separation factor was far more pronounced than that on the flux, as can be seen by comparing the separation factor for ethyl acetate [dielectric constant $(\varepsilon)=6]$, which was in the range of 5000 to 15000 (Figure 5), with that for ethanol ( $\varepsilon=24.3)$, which was as little as 50 to 200 (Figure 4). The separation factor also decreased when the weight percent of water in the mixture increased. Water flux through the membrane increased considerably as the water concentration in the solution increased (Figures 3-5), meaning that the organic flux increased even more.

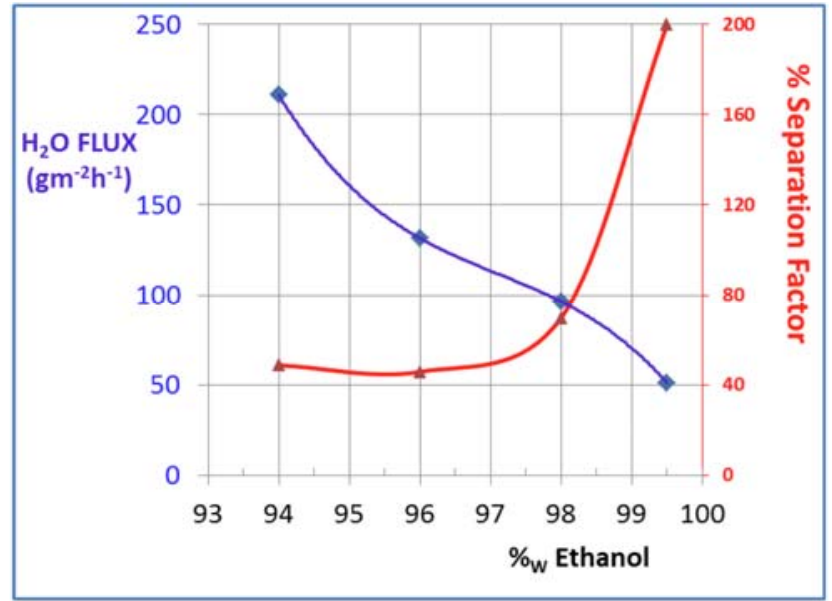

Figure 4: Water flux and Separation Factor vs. \%w of ethanol in feed for bench scale operation at $60^{\circ} \mathrm{C}$.

\subsubsection{Influence of the Solution Temperature on the Water Flux}

As the temperature of the feed solution was increased, the diffusion coefficient of the water through the membrane increased, according to the Arrhenius equation, and the water flux rose accordingly, see Figure 6. Moreover in this figure, the maximal attainable isopropyl alcohol (IPA) concentrations are shown for each temperature: $95 \%$ at $45{ }^{\circ} \mathrm{C}$ but $99 \%$ at $72^{\circ} \mathrm{C}$.

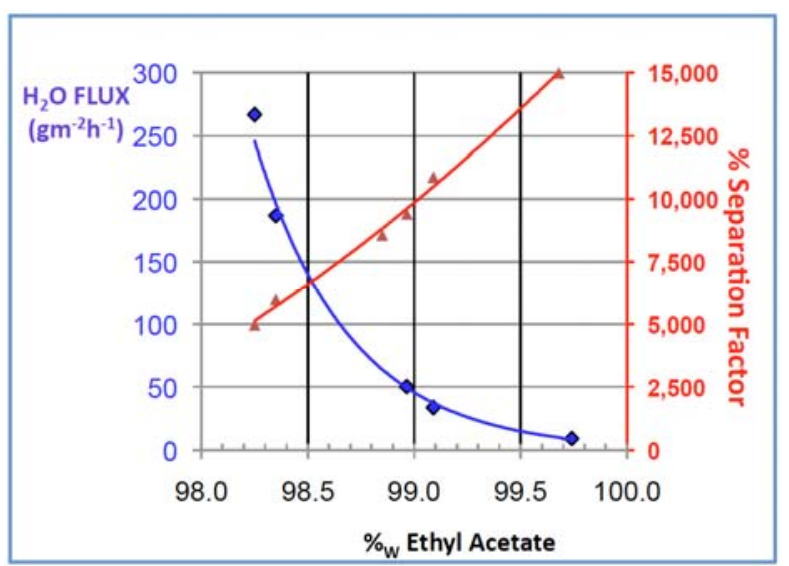

Figure 5: Water flux and separation factor vs. w \% of ethyl acetate $(\varepsilon=6)$ in the feed for bench scale operation at $60^{\circ} \mathrm{C}$.

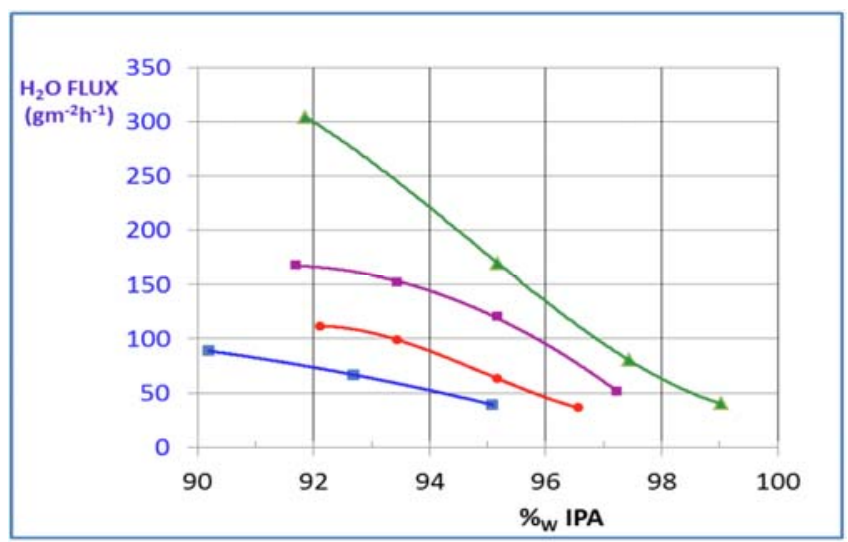

Figure 6: Water flux vs. \%w of IPA in the feed for bench-scale operation at various temperatures: $45^{\circ} \mathrm{C}-{ }^{-} ; 55^{\circ} \mathrm{C}-\bullet-; 66^{\circ} \mathrm{C}$ , - - ; $72^{\circ} \mathrm{C}-\boldsymbol{\Delta}$ - .

\subsubsection{Influence of the Membrane Thickness on the Water Flux}

As mentioned above, the flux can be increased by reducing the wall thickness without significantly impairing the mechanical strength. However, the reduction in the wall thickness will be accompanied by certain decrease of the internal diameter of the hollow fiber, which will cause an undesirable increase in pumping pressure. Therefore, the optimal conditions must be established experimentally. Our experiments confirmed a dramatic increase in the water flux with decreasing wall thickness of the hollow fiber membrane for a water-IPA mixture (Figure 7). Moreover, by reducing the wall thicknes from $100 \mu \mathrm{m}$ to $33 \mu \mathrm{m}$, the separation factor did not change significantly. 


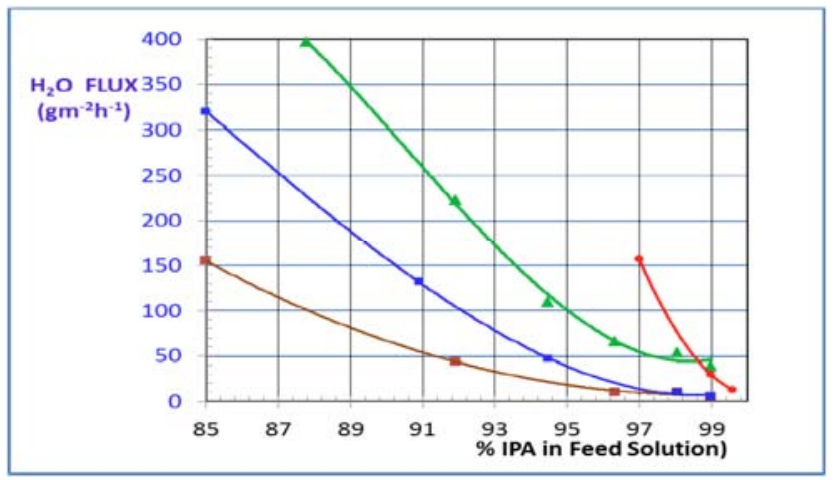

Figure 7: Water flux vs \% IPA in the feed solution for benchscale operation at $65^{\circ} \mathrm{C}$ with hollow fiber membranes of various wall thicknesses: $100 \mu \mathrm{m}--\square-; 70 \mu \mathrm{m}$-п- ; $48 \mu \mathrm{m}$ - $\Delta$ - ; $33 \mu \mathrm{m}-\bullet-$.

\subsubsection{Influence of the Cooling Temperature of the Recirculated Air on the Water Flux}

In the recirculated air sweep pervaporation process, air is cooled to allow the water vapor in the air to condense (Figure $\mathbf{1}$ ). If the concentration of water vapor in the air is too high, the water flux, which depends on the difference in water vapor pressure between the feed solution and the air, will decline. Figure 8 shows that for a highly concentrated organic solution, a high water flux could be maintained only if the air was cooled to below $0^{\circ} \mathrm{C}$, preferably to about $5^{\circ} \mathrm{C}$. At these temperatures, water vapor pressures were 4.6 and $3.2 \mathrm{~mm} \mathrm{Hg}$, respectively. In addition, as mentioned above, low water pressure on the downstream side of the membrane maintained high separation factor of the process.

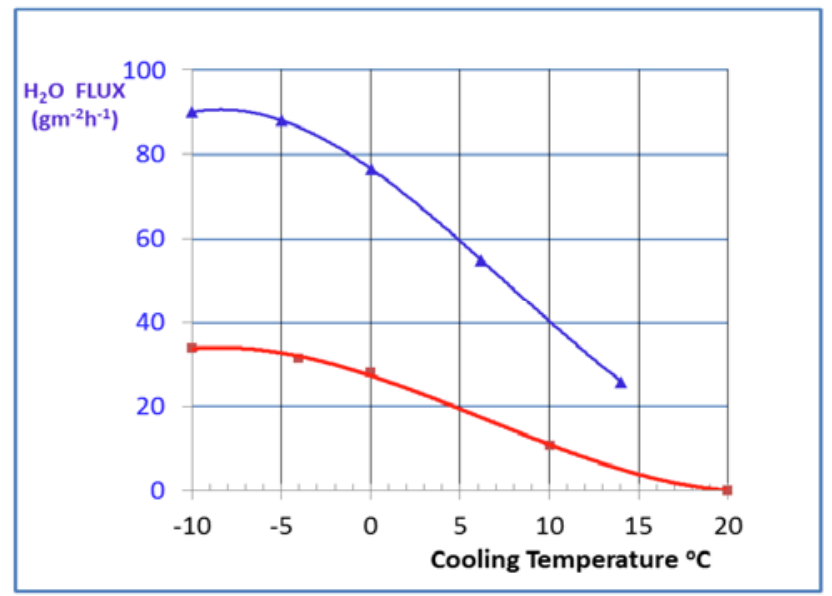

Figure 8: Water flux vs cooling temperature in bench-scale operation, with $97 \%$ ethanol solution at $60^{\circ} \mathrm{C}-{ }^{-}-$and with $99 \%$ IPA solution at $65^{\circ} \mathrm{C}-\boldsymbol{\Delta}$ - .

\subsubsection{Influence of the Air Flow Rate on the Water Flux}

The air sweep flow rate must be sufficiently high to ensure that partial water vapor pressure on the downstream side will be low enough to maintain a large drop in water vapor pressure between the waterorganic mixture on one side of the membrane and the air sweep gas on the other side of the membrane (Figure 1). Nonetheless, if the air sweep flow rate is too high, there will be a high energy demand to pump the air through the module and to heat and cool it. Therefore, the optimal conditions for each waterorganic liquid mixture have to be determined experimentally. When the concentration of water in the organic-water mixture is high, the air flow rate must be also high to 'sweep' the water vapor and to ensure a low water vapor concentration in air. For example, when the flux of water through the membrane is about $1000 \mathrm{gm}^{-2} \mathrm{~h}^{-1}$ and the maximum water concentration in the air at $55^{\circ} \mathrm{C}$ is $100 \mathrm{~g} \mathrm{~m}^{-3}$, the flow rate of air must be higher than $10 \mathrm{~m}^{3} \mathrm{~h}^{-1}$ per $\mathrm{m}^{2}$ of membrane (preferably $20 \mathrm{~m}^{3} \mathrm{~h}^{-1}$ ). However, when the water concentration in the feed mixture is low, the water flux through the membrane decreases and a lower air flow rate can be used. Figure $\mathbf{9}$ shows that when the water concentration in the feed was lower than $4 \%$, the air flow rate could be kept in the range of 3-4 $\mathrm{m}^{3} \mathrm{~h}^{-1}$ without a significant influence on the water flux.

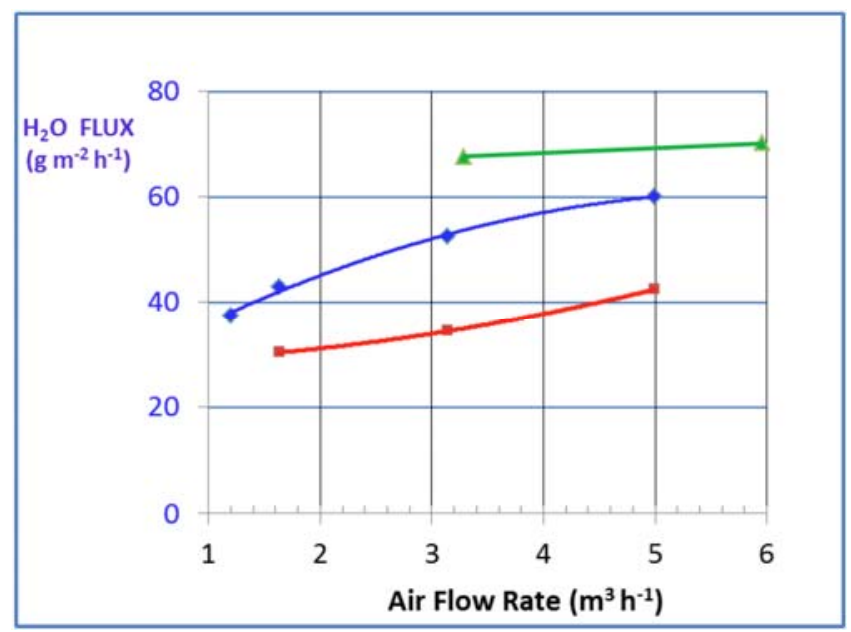

Figure 9: Water flux vs air flow rate for various concentrations of IPA solutions, .98.4\%-"-; 97.1\%-•-; 96.3\% $-\Delta-$. Bench scale operation.

\subsection{Pilot Plant Unit}

The results obtained with the pilot plant were similar to those with the benchscale operation.

\subsubsection{Influence of the Feed Flow Rate on the Water Flux}

A decrease in the feed flow rate from $540 \mathrm{lh}^{-1}$ to 270 $\mathrm{Ih}^{-1}$ did not have a significant effect on the water flux (Figure 10), which means that the polarization of the 
water concentration in the boundary layer was insignificant. For these two flow rates, the feed velocity inside the hollow fibers was low, $27 \mathrm{~cm}^{-1}$ and $13.5 \mathrm{~cm}^{-1}$, respectively, which indicates a laminar flow regime. The unit was operated for about $200 \mathrm{~h}$ (Figure 11) with IPA-water solutions, and no significant change in flux was observed during that time.

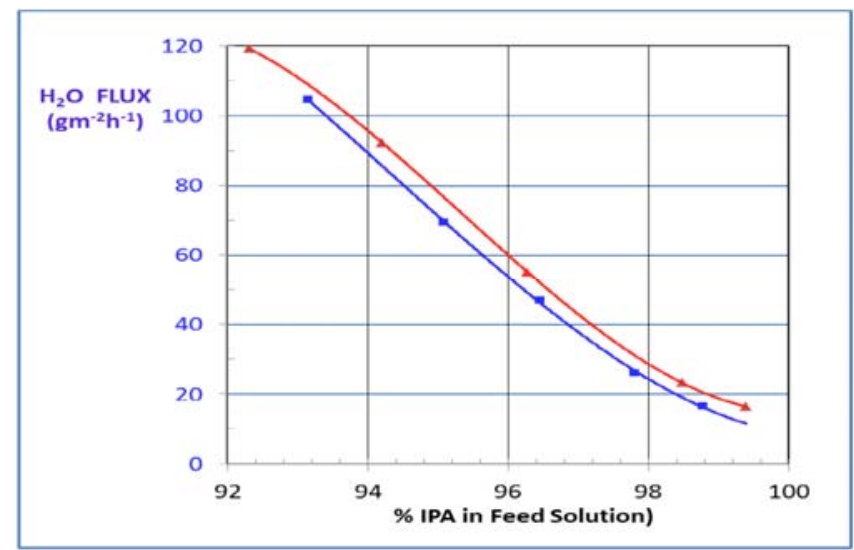

Figure 10: Water flux vs \% IPA in the feed solution operated at $60^{\circ} \mathrm{C}$ with 5 modules of $1.2 \mathrm{~m}^{2}$, at two solution flow rates: $270 \mathrm{Ih}^{1}-\mathrm{n}-$ and $540 \mathrm{lh}^{-1}-\mathrm{A}$ -

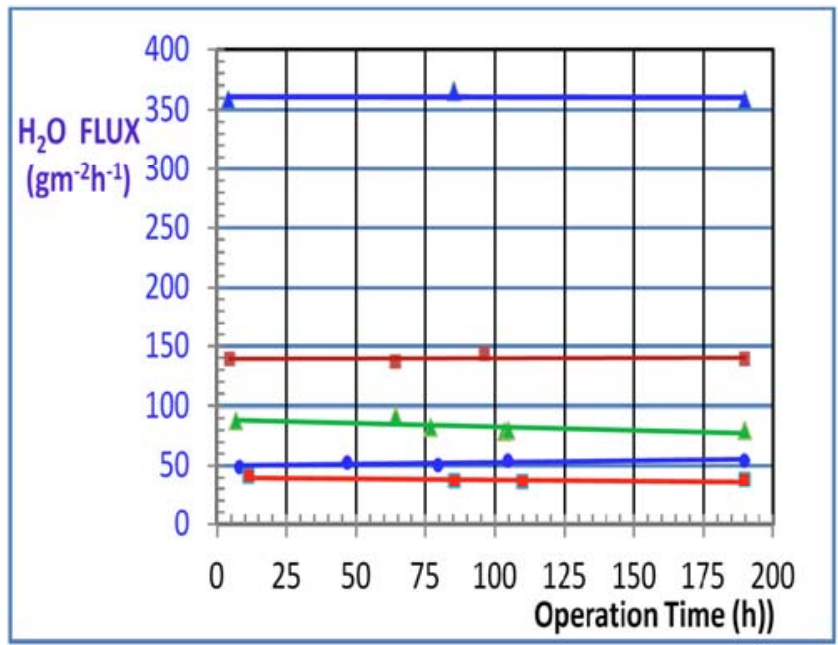

Figure 11: Water flux vs operation time of pilot plant unit that had surface area of $6 \mathrm{~m}^{2}$. Five IPA feed solutions were tested at $60{ }^{\circ} \mathrm{C}: 86.5 \%-\Delta-; 91 \%-\square-; 94 \%-\Delta--; 96 \%-\bullet-; 97 \%-\square-$. IPA concentration in the permeate was $6-12 \%$.

\subsubsection{Energy Requirement}

The energy consumption in the air sweep pervaporation process is made up of the following contributions:

water evaporation and condensation

pumping energy for air recirculation, see ref. [9]

pumping energy for solution recirculation, see ref. [9] air heating and cooling

feed solution heating.

The total energy requirement for reducing the water concentration to $0.5 \%$ from $3-10 \%$ IPA-water mixtures was between 100-225 kWh ton ${ }^{-1}$ (Figure 12).

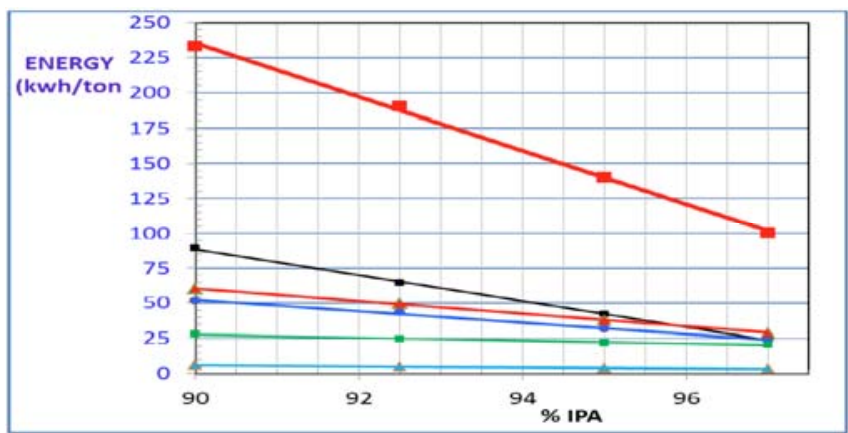

Figure 12: Energy requirements for the various operations involved in the process of increasing the IPA concentration up to $99.5 \%$ by pervaporation. Solution circulation - - - ; solution heating - - ; air heating \& cooling - - ; air circulation $\Delta$ - ; water evaporation \& condensation -a- ; total energy requirement - - . The figures are explained and detailed in [9].

\section{CONCLUSIONS AND SUMMARY}

Anion-exchange membranes proved to be suitable for extracting water from organic solutions in a recirculated air sweep pervaporation process. The following important parameters characterize the process:

1. The dielectric constant of the organic component has a very important influence on the water flux and the separation factor. When dielectric constant of the organic solvent is low, water flux and separation factor are high. Therefore, organic substances that have low dielectric constants are more suitable for dehydration by ion-exchange membranes.

2. The flux is significantly increased when the temperature of the feed solution is increased.

3. Membrane thickness considerably influences the water flux through the membrane.

4. It is possible to decrease the water concentration in an IPA solution to less than $0.5-1.0 \%$ if the temperature of the feed solution is above $65^{\circ} \mathrm{C}$ and the air cooling temperature is below $0^{\circ} \mathrm{C}$.

5. The total energy requirement to reduce the water concentration in an IPA solution from $3-10 \%$ to below $0.5 \%$ is between $100-225 \mathrm{kWh}^{-1}$. 


\section{ACKNOWLEDGEMENTS}

The research was supported, in part, by The Ministry of Industry.

\section{REFERENCES}

[1] Cabasso I, Korngold E, Lie ZZ. On the separation of alcohol/water mixtures by polyethylene ion exchange membrane. J Polym Sci Lett Edn 1985; 23: 577. http://dx.doi.org/10.1002/pol.1985.130231106

[2] Cabasso I, Korngold E. Membrane permeation process for dehydration of organic liquids mixtures using sulphonated ion-exchange polyalkene membranes. U.S.A. Patent 4728429, 1988.

[3] Freger V, Korin E, Wisniak J, Korngold E. Preferential sorption in ion-exchange pervaporation membranes; sorption of water-ethanol mixture by sodium polyethylene sulphonate. J Membrane Sci 1997; 128: 151. http://dx.doi.org/10.1016/S0376-7388(96)00306-7

[4] Freger V, Korin E, Wisniak J, Korngold E. Transport mechanism in ion exchange pervaporation membranes. $J$ Membr Sci 1997; 133: 255.

http://dx.doi.org/10.1016/S0376-7388(97)00080-X
[5] Freger V, Korin E, Wisniak J, Korngold E, Ise M, Kreuer KD. Diffusion of water and ethanol in ion- exchange membrane: limits of the geometric approach. J Membr Sci 1999; 160: 213-224.

http://dx.doi.org/10.1016/S0376-7388(99)00084-8

[6] Freger V, Korin E, Wisniak J, Korngold E. Measurement of sorption in hydrophilic pervaporation: sorption modes and consistency of the data. J Membr Sci 2000; 164: 251-256. http://dx.doi.org/10.1016/S0376-7388(99)00198-2

[7] Korngold E, Zisner E, Wachs R. Separation of component of organic liquids. Israel Patent No 129163 (2002). U.S.A. patent No. 6913696 (2005)

[8] Kujawski W, Krajewski SR. Sweeping gas pervaporation with hollow-fiber ion-exchange membranes. Desalination 2004; 162(1-3): 129-135. http://dx.doi.org/10.1016/S0011-9164(04)00036-0

[9] Korngold E, Korin E, Ladizhensky I. Water desalination by pervaporation with hollow fiber membranes. Desalination 1996; 107: 121-129.

http://dx.doi.org/10.1016/S0011-9164(96)00157-9

[10] Korin E, Ladizhensky I, Korngold E. Hydrophilic hollow fiber membranes for water desalination by the pervaporation method. Chem Eng Process 1996; 35: 451-457. http://dx.doi.org/10.1016/S0255-2701(96)04157-8

[11] Ion Exchange, By: Helfferich, Friedrich G. New York: McGraw-Hill, 1962; p. 624.

Received on 26-01-2016

Published on 25-07-2016

\section{DOI: http://dx.doi.org/10.6000/1929-6037.2016.05.02.3}

(C) 2016 Korngold et al.; Licensee Lifescience Global.

This is an open access article licensed under the terms of the Creative Commons Attribution Non-Commercial License (http://creativecommons.org/licenses/by-nc/3.0/) which permits unrestricted, non-commercial use, distribution and reproduction in any medium, provided the work is properly cited. 